\title{
References
}

1 Herth FJ, Eberhardt R, Gompelmann D, et al. Radiological and clinical outcomes of using Chartis ${ }^{\mathrm{TM}}$ to plan endobronchial valve treatment. Eur Respir J 2013; 41: 302-308.

2 Sciurba FC, Ernst A, Herth FJ, et al. A randomized study of endobronchial valves for advanced emphysema. $N$ Engl J Med 2010; 363: 1233-1244.

3 Ninane V, Geltner C, Bezzi M, et al. Multicentre European study for the treatment of advanced emphysema with bronchial valves. Eur Respir J 2012; 39: 1319-1925.

4 Herth FJ, Noppen M, Valipour A, et al. Efficacy predictors of lung volume reduction with Zephyr valves in a European cohort. Eur Respir J 2012; 39: 1334-1342.

5 Valipour A, Herth FJF, Burghuber OC, et al. Target lobe volume reduction and COPD outcome measures after endobronchial valve therapy. Eur Respir J 2014; 43: 387-396.

6 Gompelmann D, Eberhardt R, Slebos D-J, et al. Comparison between Chartis pulmonary assessment system detection of collateral ventilation $v s$ corelab CT fissure analysis for predicting atelectasis in emphysema patients treated with endobronchial valves. Eur Respir J 2011; 38: Suppl. 55, 631s-632s.

7 Lindquist S, Chung S, Peters M, et al. Chartis evaluation of collateral ventilation versus HRCT assessment, in predicting clinical outcomes following endobronchial valve therapy (EBV) in COPD patients. Eur Respir J 2012; 40: Suppl. 56, 864s.

\section{Infant lung function and wheeze in later childhood in the Southampton Women's Survey}

\author{
To the Editor:
}

We were interested to read the study by VAN DER GUGTEN et al. [1] reporting associations between increased neonatal respiratory resistance and wheezing illnesses during infancy, and between reduced neonatal respiratory compliance and wheezing illnesses during the first 5 years of life and late-onset and persistent wheeze phenotypes. Reduced respiratory compliance was also associated with asthma, defined both according to primary care consultations and prescriptions or referral for wheezing illnesses, and according to patient-reported symptoms and lung function at the age of 5 years. The authors proposed that compliance and resistance might reflect different lung characteristics that are associated with symptoms in different age periods. Our data from normal-term infants in the Southampton Women's Survey birth cohort provide further evidence that impaired physiological measurements soon after birth are associated with specific wheeze phenotypes. We previously reported an association between lower maximal flow at functional residual capacity $\left(V^{\prime} \max _{\mathrm{FRC}}\right)$ in early infancy and later transient wheeze [2]. The paper by VAN DER GUGTEN et al. [1] has led us to analyse our data further with regards to compliance of the respiratory system (Crs) and we have found that lower $C$ rs is associated with asthma in our cohort too. Using the raised volume thoracoabdominal compression technique, we also measured forced expiratory volume in $0.4 \mathrm{~s}$ (FEV0.4); lower FEV0.4 measurements were associated with increased childhood asthma risk.

We have previously described our methods [3]. In brief, lung function was measured between 5 and 14 weeks of age in 147 term infants. Infants were tested lying supine in quiet sleep, augmented by oral chloral hydrate $\left(75-100 \mathrm{mg} \cdot \mathrm{kg}^{-1}\right) . V^{\prime} \max _{\mathrm{FRC}}$ and $\mathrm{FEV} 0.4$ were calculated from partial and raised volume expiratory flow-volume curves, respectively. Crs was calculated from passive flow-volume curves following single occlusions. Wheeze data were collected at 6, 12, 24 and 36 months and 6 years using questions from the ISAAC (International Study of Asthma and Allergies in Childhood) core questionnaire wheezing module. 95 children provided questionnaire data and spirometry at age 6 years. Associations between infant lung function measurements and wheeze phenotype were assessed using regression; significant confounders were included in multivariable models (as described in [2]). Table 1 shows an association between lower early infancy $C r$ and childhood asthma together with an association between lower $V^{\prime} \max _{\mathrm{FRC}}$ and transient wheeze. The former confirms the finding of VAN DER GUGTEN et al. [1] of reduced early-life Crs in children later diagnosed with asthma and the latter; although not identical to the findings of VAN DER GUGTEN et al. [1], it is, however, consistent with their proposal that low airway calibre is a likely contributor to wheeze 
TABLE 1 Mean infant lung function values according to wheeze phenotype determined at 6-year follow-up

\begin{tabular}{|c|c|c|c|}
\hline Phenotype & $V^{\prime} \max _{\mathrm{FRC}}$ & FEV 0.4 & Crs \\
\hline \multicolumn{4}{|l|}{ Asthma } \\
\hline No & 1 (ref.) & 1 (ref.) & 1 (ref.) \\
\hline Yes & $0.76(0.54-1.07)$ & $0.83(0.71-0.97)^{*}$ & $0.86(0.74-0.99) *$ \\
\hline \multicolumn{4}{|l|}{ Wheeze } \\
\hline Never & 1 (ref.) & 1 (ref.) & 1 (ref.) \\
\hline Transient & $0.71(0.58-0.88) *$ & $0.96(0.87-1.00)$ & $0.96(0.88-1.05)$ \\
\hline Late & $0.84(0.32-2.22)$ & $1.11(0.76-1.62)$ & $1.01(0.71-1.42)$ \\
\hline Persistent & 0.67 (0.43-1.05) & $0.93(0.76-1.12)$ & $0.97(0.83-1.15)$ \\
\hline
\end{tabular}

Data are presented as ratio geometric mean $(95 \% \mathrm{Cl})$. Relationships between maximal flow at functional residual capacity ( $\mathrm{V}^{\prime} \mathrm{max}_{\mathrm{FRC}}$ ), forced expiratory volume in $0.4 \mathrm{~s}$ (FEV 0.4 ) and compliance of the respiratory system ( $\mathrm{Crs}_{\mathrm{rs}}$ ) with asthma and wheeze phenotypes are presented. Measures of infant lung function were adjusted for age and sex where necessary and logarithmically transformed to achieve normality. Those who never wheezed formed the reference (ref.) group for transient late and persistent wheeze, while never asthma was the reference for asthma. Linear regression was adjusted for significant confounders [2]. *: $p<0.05$.

symptoms in infancy. In contrast to VAN DER GUGTEN et al. [1], we did not find an association between Crs and persistent wheeze.

The study by VAN DER GUGTEN et al. [1] employed the minimally invasive single-breath occlusion technique to measure lung function; follow-up data included spirometry and information collected from general practitioners' electronic patient files. Strengths of this approach are large sample size (549 infants) and availability of data describing symptom frequency. Our study included additional measurements of forced expiratory flows but respiratory resistance and wheeze frequency data were not available. Our asthma outcome was not directly comparable to that of VAN DER GUGTEN et al. [1], as it was based upon a doctor's diagnosis irrespective of primary care contacts, current symptoms or medications.

Impaired neonatal lung function, characterised by reduced values for the fraction of expiratory time to peak tidal expiratory flow to total expiratory time, has previously been found to be associated with childhood asthma [4]. Our approach is unique, however, in employing the raised volume thoracoabdominal compression technique to consider the relationship between timed expiratory flows measured soon after birth and asthma later in childhood. We found that reduced FEV0.4 was associated with asthma but not with other wheeze phenotypes.

VAN DER GUGTEN et al. [1] found higher neonatal resistance of the respiratory system and lower neonatal Crs to be associated with lower childhood FEV1 and forced expiratory flow at 25-75\% of forced vital capacity (FEF25-75\%). Within our cohort, both $V^{\prime} \max _{\mathrm{FRC}}$ and FEV0.4 were positively associated with childhood FEV1 and $\mathrm{FEF} 25-75 \%\left(V^{\prime} \max _{\mathrm{FRC}} \mathrm{p}=0.001\right.$ and $\mathrm{p}<0.001$, respectively; FEV0.4 $\mathrm{p}=0.049$ and $\mathrm{p}=0.041$, respectively); $\mathrm{Crs}$ soon after birth was not significantly associated with these spirometric measurements. This difference between the two studies may reflect a lack of power in our smaller study, since a closer relationship could be expected between forced expiratory flows in infancy and childhood, given that airway calibre is a significant determinant of each of these measurements.

Tracking of lung function suggests relative impairment of lung function persists from early infancy to childhood, yet investigation of the relationship between infant lung function and phenotypes of wheezing illness, as noted by VAN DER GUGTEN et al. [1], has produced conflicting results. Analysis of 125 infants enrolled in the Tucson Children's Respiratory Study found reduced $V^{\prime} \max _{\mathrm{FRC}}$ during early infancy in individuals wheezing transiently at or before age 3 years, but no association was found with wheezing beyond 3 years of age [5]. In contrast, a study from Perth, Australia, found reduced $V^{\prime} \max _{\mathrm{FRC}}$ in infancy to be associated with persistent but not transient wheeze [6]. These differences may reflect variation in infant lung function techniques, correction for body size, age of outcome or the genetic predisposition of the population. Importantly, where invasive techniques have been used, this has limited study size. Broad wheeze phenotypes are likely to be heterogeneous and variable contributions from separate subphenotypes across relatively low-powered studies may give rise to conflicting results. In support of this heterogeneity, we have we have previously presented data suggesting that the traditional persistent wheeze category contains a mix of individuals, only some of whom, those with onset of persistent wheeze before 1 year of age, have relative lung function impairment from birth [2]. 
We are grateful to VAN DER GUGTEN et al. [1] for the opportunity to compare our findings with those from a larger cohort. While previous studies have demonstrated reduced lung function soon after birth in individuals who wheeze in infancy $[7,8]$, the relationship between infant lung function and wheezing disorders beyond infancy is less clear [5,6]. The findings of VAN DER GUGTEN et al. [1] in conjunction with those from the Southampton Women's Survey provide evidence that structural airway impairments in infancy may differentially predict asthma and wheeze in childhood.

0 @ERSpublications

Structural airway impairments in infancy may differentially predict asthma and wheeze in childhood http://ow.ly/qt3cw

Emily Brooke ${ }^{1}$, Jane S.A. Lucas ${ }^{1,2}$, Samuel A. Collins ${ }^{1,2}$, John W. Holloway ${ }^{1,3}$, Graham Roberts ${ }^{1,2,3}$, Hazel Inskip ${ }^{3,4}$, Keith M. Godfrey ${ }^{3,4,5}$, Cyrus Cooper ${ }^{3,4,5}$, Katharine C. Pike ${ }^{1,2}$ and the Southampton Women's Survey Study Group ${ }^{1}$ Clinical and Experimental Sciences Academic Unit, Faculty of Medicine, University of Southampton, Southampton, ${ }^{2}$ NIHR Southampton Respiratory Biomedical Research Unit, University of Southampton and University Hospital Southampton NHS Foundation Trust, Southampton, ${ }^{3}$ Human Development and Health Academic Unit, Faculty of Medicine, University of Southampton, Southampton, ${ }^{4}$ Medical Research Council Lifecourse Epidemiology Unit, University of Southampton, Southampton, and ${ }^{5}$ NIHR Southampton Biomedical Research Centre, University of Southampton and University Hospital Southampton NHS Foundation Trust, Southampton, UK.

Correspondence: J.S.A. Lucas, Clinical and Experimental Sciences Academic Unit, Faculty of Medicine, University of Southampton, Southampton S016 6YD, UK. E-mail: jlucas1@soton.ac.uk

Received: July 302013 | Accepted after revision: Aug 272013

Conflict of interest: Disclosures can be found alongside the online version of this article at www.erj.ersjournals.com

\section{References}

1 van der Gugten AC, Uiterwaal CS, van Putte-Katier N, et al. Reduced neonatal lung function and wheezing illnesses during the first 5 years of life. Eur Respir J 2013; 42: 107-115.

2 Collins SA, Pike KC, Inskip HM, et al. Validation of novel wheeze phenotypes using longitudinal airway function and atopic sensitization data in the first 6 years of life: evidence from the Southampton Women's Survey. Pediatr Pulmonol 2013; 48: 683-692.

3 Lucas JS, Inskip HM, Godfrey KM, et al. Small size at birth and greater postnatal weight gain: relationships to diminished infant lung function. Am J Respir Crit Care Med 2004; 170: 534-540.

4 Haland G, Carlsen KC, Sandvik L, et al. Reduced lung function at birth and the risk of asthma at 10 years of age. N Engl J Med 2006; 355: 1682-1689.

5 Martinez FD, Wright AL, Taussig LM, et al. Asthma and wheezing in the first six years of life: relation with lung function, total serum IgE levels and skin test reactivity to allergens. N Engl J Med 1995; 332: 133-138.

6 Turner SW, Palmer LJ, Rye PJ, et al. The relationship between infant airway function, childhood airway responsiveness, and asthma. Am J Respir Crit Care Med 2004; 169: 921-927.

7 Martinez FD, Morgan WJ, Wright AL, et al. Diminished lung function as a predisposing factor for wheezing respiratory illness in infants. N Engl J Med 1988; 319: 1112-1117.

8 Pike KC, Rose-Zerilli MJ, Caffrey Osvald E, et al. The relationship between infant lung function and the risk of wheeze in the preschool years. Pediatr Pulmonol 2011; 46: 75-82.

Eur Respir J 2014; 43: 919-921 | DOI: 10.1183/09031936.00131613 | Copyright @ERS 2014

\section{From the authors:}

We would like to thank E. Brooke and co-workers for their interest in our article [1] and for the interesting study they performed. Their data from the Southampton Womens' Survey provide further evidence that an impaired neonatal lung function is associated with respiratory symptoms [1, 2]. Also, in their cohort, a lower neonatal compliance of the respiratory system was associated with asthma in childhood [1]. Additionally, they were able to measure the forced expiratory flow in $0.4 \mathrm{~s}$ (FEV0.4) by using the raisedvolume thoraco-abdominal compression technique. Also, lower FEV0.4 measurements were found to be associated with increased childhood asthma risk [1].

Although longitudinal cohort studies are challenging, they enable us to study repeated observations of the same person at different points in time. Such studies allow us to track the changes of early-life lung function at the individual level in relation to respiratory symptoms in childhood. With longer follow-up, direct study of associations between neonatal lung function and the occurrence of adult respiratory diseases, such as chronic obstructive pulmonary disease, will be possible.

Studies performed to date, including the Southampton Women's Survey, clearly underline the importance of measuring lung function starting at birth. Although these measurements are challenging, new devices 